\title{
Erratum to: The chemistry of some foliar litters and their sequential proximate analysis fractions
}

\author{
Caroline M. Preston · J. A. Trofymow
}

Published online: 9 September 2016

(C) Springer International Publishing Switzerland 2016

Erratum to: Biogeochemistry (2015) 126:197-209 DOI 10.1007/s10533-015-0152-x

Except for fescue, the values in the right hand column of Table 1 (CT fr ext) were incorrectly assigned by species. The correction (below) does not affect the relevant text but allows readers to generate correct values of extractable and residual tannins in each sample. 


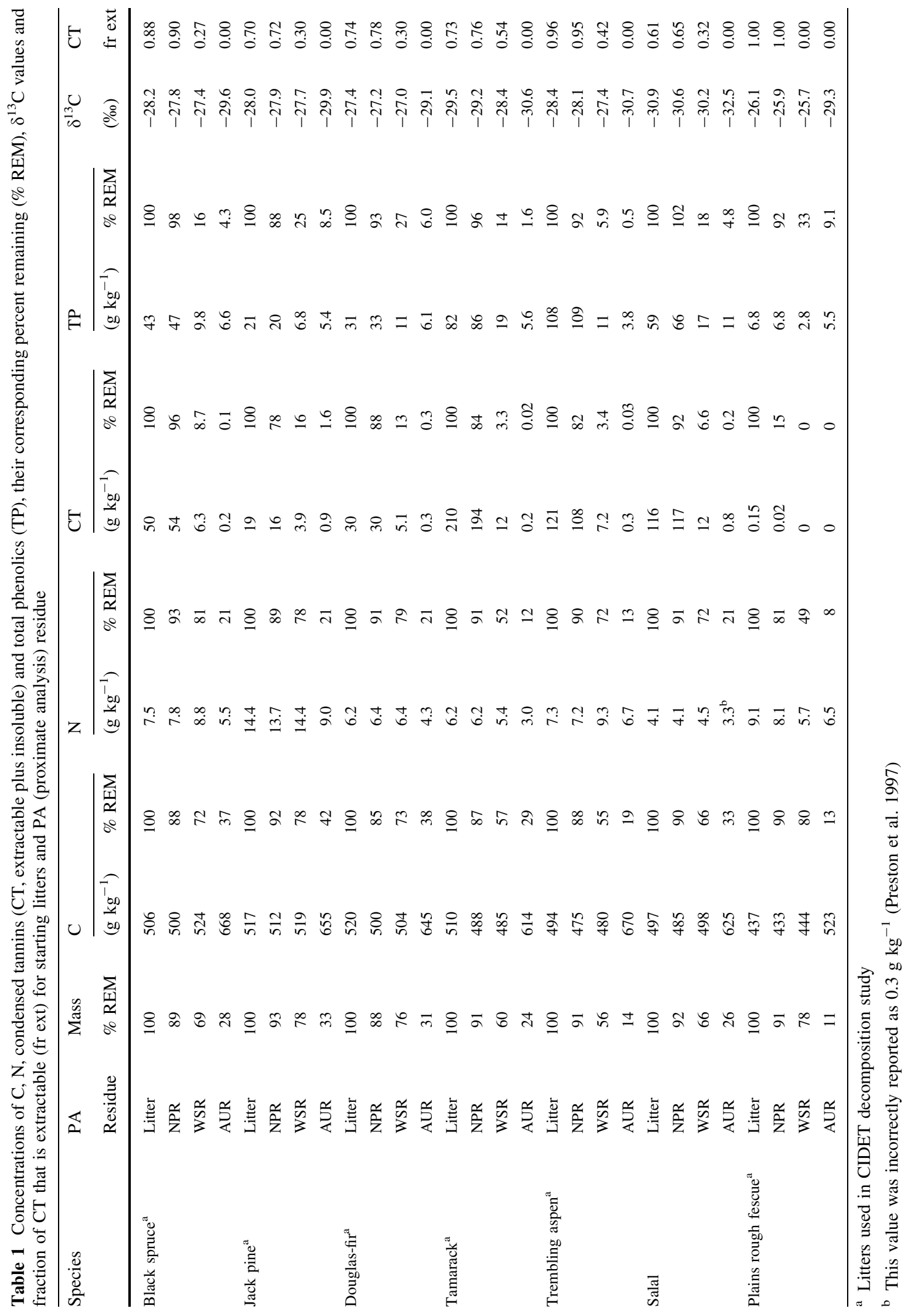

